\title{
BIM and Aerial Photogrammetry: building documentation of E1 - USP São Carlos
}

\section{SIGRADI2018 TECHNOPOLITICAS \\ xxii congresso da sociedade iberoamericana de gráfica digital 22th conference of the iberoamerican society of digital graphics 07|08|09|novembro|2018 iau usp | são carlos | sp br}

\author{
Júlio César Franco Júnior \\ Universidade de São Paulo | Brazil | julio.frc@gmail.com \\ Heliara Aparecida Costa \\ Universidade Federal do Tocantins, Universidade de São Paulo | Brazil | heliara@uft.edu.br
}

Márcio Minto Fabrício

Universidade de São Paulo | Brazil | marcio@sc.usp.br

\begin{abstract}
This article demonstrates the integration process of aerial photogrammetry and BIM technologies for the purpose of supplying gaps in building documentation, resulting of changes during use-operation and maintenance of a historical building; as well as to record and document the project for future demands. For that, a research field was carried out with a RPAS - Remotely Piloted Aircraft Systems; and a study of the case of the E1 building, at USP São Carlos, a representative of the modern brazilian architecture, with few sources of information. The results demonstrate a satisfactory quality in the generation of orthomosaics for building documentation and consistent record for BIM as-is models
\end{abstract}

Keywords: Aerial Photogrammetry; BIM; Building documentation.

\section{INTRODUÇÃOO}

As novas tecnologias digitais vêm revolucionando o setor de Arquitetura, Engenharia, Construção e Operações (AECO), tanto no processo de concepção e representação do projeto, quanto no processo construção e gestão. Os benefícios são visíveis principalmente para edificações novas. Da mesma forma, essas tecnologias também vêm ganhando espaço na conservação, restauro e registro de edificações já construídas, incluindo aí as históricas (DEZEN-KEMPTER et al., 2015).

As edificações históricas são de extrema relevância pelo seu significado cultural e por fazerem parte do estoque dos imóveis em uso. No entanto - muitas vezes são necessárias - além de conservação e restauro adequações para uma perfeita habitabilidade e sustentabilidade no contexto em que se insere. Uma das barreiras para esse processo é a obtenção da documentação as-built e as-is desses edifícios, visando simulações e dados das interferências realizadas no período de construção e pós-uso e, ao mesmo tempo, assertividade nas propostas de projeto de intervenção.

Fotogrametria Digital e Tecnologias BIM (Building Information Modeling) são ferramentas que auxiliam e facilitam no processo de obtenção de dados de edificação já construídas, considerando alterações no momento de sua construção e interferências durante o uso. Por meio da Fotogrametria é possível obter desenhos, modelos geométricos, fotos retificadas e ortomosaicos a partir de fotografias do objeto de interesse (GUIMARÃES et al, 2012). Por sua vez, o BIM é uma tecnologia de modelagem e um conjunto associado de processos para produzir, comunicar e analisar modelos de construção (EASTMAN et al., 2014, p.13).
Um dos benefícios do BIM na pós-construção é ter uma fonte precisa de informações e um ponto de partida muito útil para o gerenciamento e operação (EASTMAN et al., 2014).

Alguns estudos vêm retratando o uso dessas tecnologias em prédios históricos. Canuto, Moura e Salgado (2017) apresentam as vantagens no uso de fotogrametria, escaneamento a laser e integração com BIM, Realidade Aumentada e Realidade Virtual, por meio de estudo de caso de edifício patrimônio. Dezen-Dempter et al (2015), demonstram a integração de tecnologias híbridas de levantamento - como 3D laser scanner, fotogrametria para a captura do estado real de uma edificação histórica e sua modelagem em BIM. Na mesma direção, Guimarães, Grotetelaars e Amorim (2012) discutem estudos realizados para obtenção de dados geométricos de uma edificação já existente com uso das tecnologias de Fotogrametria Digital, Dense Stereo Matching (DSM) e modelagem em BIM.

Desta forma, o objetivo deste trabalho é demonstrar o processo de integração dos resultados gerados por um levantamento aerofotogramétrico (Nuvem de Pontos e Ortomosaicos) com um modelo BIM, de uma edificação já construída e histórica, para fins de preencher lacunas de informações projetuais, ou decorrentes de alterações durante seu uso e operação; bem como registrar e documentar o projeto para possíveis demandas futuras. 0 método usado foi levantamento de campo e estudo de caso do edifício E1 localizado no campus da Universidade de São Paulo (USP), em São Carlos, construído nos anos de 1950, e que representa um exemplar icônico da arquitetura moderna brasileira, com poucas fontes de informação de seu projeto as-built e estado as-is. 


\section{FOTOGRAMETRIA}

De acordo com Fritsch (1999), fotogrametria é uma ciência e tecnologia de aquisição e processamento de imagens fotográficas para determinação de formas, posição e características geométricas a fim de gerar modelos virtuais tridimensionais. Ciência de mensuração do campo de geodesia e sensoriamento remoto [SR], a fotogrametria utiliza técnicas para obter informações geométricas de objetos representados em fotografias (LINDER, 2009). Groetelaars (2015) reitera que por meio da fotogrametria digital é possível obter grande quantidade de dados como medidas, desenhos, modelos geométricos (com ou sem texturas), fotos retificadas, ortofotos, de acordo com a técnica utilizada.

Nos últimos 10 anos, a restituição fotogramétrica aliada ao avanço de tecnologias digitais, permitiram o desenvolvimento de uma nova técnica fotogramétrica, chamada de Dense Stereo Matching (DSM). Seu princípio de funcionamento "consiste na correlação automática de conjuntos de pixeis homólogos em fotos distintas para obtenção das coordenadas tridimensionais de pontos contidos na superfície dos objetos fotografados, gerando assim, o modelo geométrico de nuvem de pontos" (GROETELAARS, AMORIM, 2012, pag.361).

De acordo com Groetelaars (2015), a fotogrametria possui como aspecto positivo o pouco tempo despendido na coleta de campo, uma vez que a restituição das imagens é feita em ambiente computacional. Outro fator apontado positivamente, de modo geral, é a capacidade de levantamento com equipamentos de baixo custo, proporcionado pelo acesso às tecnologias como VANT (conhecidos como drones) e celulares do tipo smartphone, além de softwares de livre acesso ou de custo acessível

A técnica de levantamento de dados por fotogrametria é aplicada na obtenção de dados de edifícios já construídos, especialmente os históricos, dada a dificuldade de se obter registros e documentos de projeto as built e as is. De acordo com Dezen-Kempter et al. (2015), é necessário um processo de engenharia reversa para a reconstrução de um projeto de uma edificação existente, em que a partir de informações reais se chega à reconstrução e intepretação da ideia anterior à sua realização. Se antes, esses processos eram manuais, morosos e pouco precisos, com as tecnologias digitais tem se acrescido precisão e automatização no trabalho de levantamento e reconstrução por meio de uma nuvem de pontos que simula a edificação.

Apesar de suas vantagens, a "nuvem de pontos" gerada pela técnica DSM é menos precisa e densa que o escaneamento a laser, por exemplo. Também é limitado quanto à extração de produtos, como desenhos 2D ou $3 D$, entre outros. Suas vantagens estão na geração de dados a partir de levantamentos rápidos e com significativa precisão, permitindo a tomada de medidas para reconstrução do projeto a custos menores - quando comparados com tecnologias de escaneamento com laser.

A integração da fotogrametria com outras tecnologias para a geração do modelo e do projeto é uma questão importante a ser testada e avaliada. Nesse sentido, softwares sob o conceito BIM apresentam-se como potencial no desenvolvimento de projeto de edificações históricas em seu estado real.

\section{BIM}

Building Information Modeling (BIM) "é um dos desenvolvimentos mais promissores na indústria da construção" (Eastman, et al., 2014, p. 1) e representa uma quebra de paradigma no processo do projeto e construção não apenas como meio de representação gráfica na obtenção de documentos 2D e 3D, mas também como método de gerenciamento das informações relativas ao edifício, o seu processo de concepção e construção e também as fases de utilização e manutenção ao longo de todo o seu ciclo de vida (PENTTILÄ, RAJALA; FREESE, 2007). A principal diferença está no fato de que BIM não desenha, como nas ferramentas CAD, mas simula virtualmente o edifício, constituindo-se num modelo integrado, fornecendo um conjunto de dados e nível de precisão real do edifício que será construído.

No entanto, o uso do BIM não se limita apenas ao edifício em seu estado futuro. O BIM também tem um forte potencial para uso em edificações já construídas, como no caso das históricas, para sua Gestão e Manutenção (G\&M). A modelagem em BIM de um edifício real pode otimizar as análises necessárias sobre o estado do edifício, além de registrar um histórico das alterações decorrentes de reformas, manutenção e novos usos que se apresentam ao longo de anos. De acordo com Eastman et al. (2014), o modelo BIM representa uma ferramenta das mais importantes para a gestão do projeto as built.

A esse respeito, Denzem-Kempter et al. (2015) destacam que os benefícios do uso do BIM são significativos para a mitigação de riscos, documentação de inventário, gestão de espaço e energia, planejamento de retrofit e monitoramento dimensional na construção.

A questão fundamental é o método para tomada de informações da obra edificada, em seus detalhes, para sua simulação em BIM. Neste caso, é necessário a integração de outras ferramentas que auxiliem na aquisição desses dados reais para posterior incorporação em software BIM. O método tradicional de coleta de dados demanda um trabalho bastante moroso e impreciso, com uso de trenas e aferições manuais, que podem levar no cometimento de erros e falhas, gerando dados que refletem na qualidade e no objetivo final da G\&M.

Conforme já comentado no tópico anterior, a captura de medidas reais de um edifício pode ser automatiza a partir de tecnologias por fotogrametria e escaneamento a laser. A integração de modelos BIM com modelos fotogramétricos podem ser uma solução para garantir ao edifício já construído maior nível de precisão e, ao mesmo tempo, menor tempo no levantamento.

No entanto, Denzem-Kempter et al. (2015) inferem que os métodos de reconhecimento de objetos frutos de levantamentos com tecnologias por varredura ainda estão em fase de solução. Acrescenta-se nesse caso que os métodos por fotogrametria também necessitam serem 
avaliados. Sendo o BIM uma tecnologia bastante promissora e que vem ganhando espaço no setor AECO, importante que tais avaliações busquem a integração dessas duas ferramentas (fotogrametria + BIM), fato que motivou a realização deste estudo.

\section{O ESTUDO DE CASO: E1}

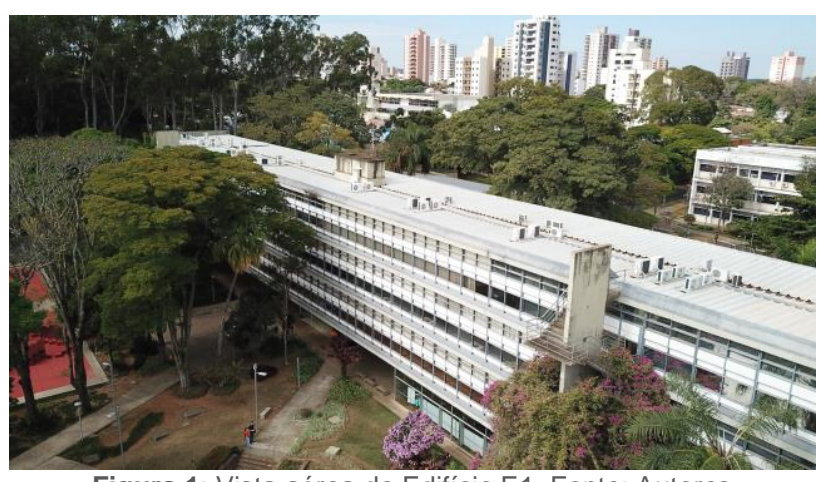

Figura 1: Vista aérea do Edifício E1. Fonte: Autores.

O edifício E1 (figura 1) é o primeiro prédio construído no campus da USP São Carlos, com obras iniciadas em 1954, de autoria do arquiteto Hélio de Queiroz Duarte (1906-1989) e engenheiro Ernest de Carvalho Mange (1922-2005). Por ser um marco inicial do campus da Escola de Engenharia, foi projetado para ser uma referência em inovações tecnológicas e para servir de modelo para os demais prédios (NOBRE, 2007).

O modelo E1 foi idealizado com grande influência dos princípios da arquitetura moderna e pelos ideais da industrialização, especialmente pelas ideias do arquiteto Le Corbusier, cujas obras Mange teve a oportunidade de acompanhar, por meio de um estágio no ATBAT/Atelier de Batusseurs (NOBRE, 2007). Tais princípios pautam-se pela "racionalidade, funcionalidade, flexibilidade dos espaços, integração social e cultural, e na utilização da tecnologia moderna (concreto armado, aço, vidro, etc.)" (NOSELLA, BUFFA, 2000, pag. 58). O edifício possui quatro pavimentos com estrutura de concreto; fachadas em sistema de janela cortina em aço; planta racionalizada em módulo de $70 \mathrm{~cm}$; plantas livres e flexíveis, que já acomodaram diferentes funções, de salas de aulas à atual administração da Escola de Engenharia de São Carlos. Possui um sistema de visita às instalações, por meio de uma calha central nas lajes dos pavimentos que descem pelos pilares, como forma de facilitar a sua manutenção. Importante ainda citar que o último piso seguia o conceito de teto jardim, como uma área para ser explorada para usos diversos permitindo o uso e acesso a este nível da edificação por meio das escadas externas.

A construção do edifício abrangeu o período de 1954 a 1957, contrariando os seis meses previstos. As inovações tecnológicas do projeto foram apontadas como um dos fatores responsáveis pelo atraso (NOBRE, 2007). Se o E1 não cumpriu sua função de ser um modelo replicado no campus, consolidou-se como um importante representante da arquitetura moderna brasileira.

A motivação para usar o E1 como estudo de caso desta pesquisa justifica-se por este ser um exemplar do patrimônio moderno brasileiro, ainda pouco retratado pela academia, e que vem passando por alterações ao longo de seus mais de 60 anos de existência. Entre essas mudanças, é visível atualmente a cobertura do teto jardim com telha metálica. Desta forma, considera-se importante registrar os aspectos atuais da edificação, como projeto as-is, e ao mesmo tempo fonte de informações para futuras manutenções e pesquisas.

\section{MATERIAIS E MÉTODO}

Neste estudo os equipamentos e softwares utilizados foram:

- $\quad$ Drone DJI Mavic Pro;

- Agisoft Photoscan v1.4.2: software utilizado para processar as imagens capturadas pelo drone e gerar os modelos tridimensionais;

- Autodesk Revit 2018: software utilizado para modelagem BIM e integração de modelos.

O método utilizado no presente trabalho é apresentado na Figura 1. Na etapa Planejamento foram realizadas visitas no local para avaliação do entorno, identificação de riscos, obstáculos e local de pouso/decolagem. Essa etapa incluiu também a solicitação de autorização da administração local, seguida do estabelecimento do plano de voo necessário para as visadas do levantamento. $\mathrm{Na}$ etapa seguinte, foram realizados voos de captura para que, em laboratório, o Processamento de imagens fosse realizado no software Agisoft PhotoScan 1.4.2 e os resultados integrados em um modelo BIM, no Autodesk Revit 2019.

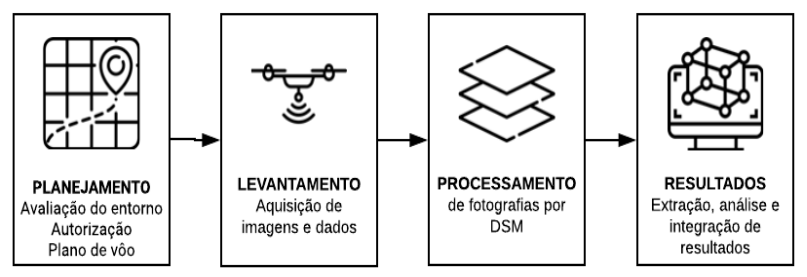

Figura 2: Fluxograma de etapas do trabalho. Fonte: autores.

Para levantamento de dados espaciais da edificação, utilizou-se Aeronave Remotamente Pilotada (drone), modelo DJI Mavic-Pro. O Mavic-Pro possui distância máxima de viagem aproximada de $13 \mathrm{~km}$ e tempo de voo aproximado de 20 minutos por bateria, em condições de pouco vento. $\mathrm{O}$ drone é equipado com uma câmera digital integrada, com estabilizador mecânico de três eixos, e resolução de 12.35 megapixels. O controle remoto permite acoplar um smartphone para controle das tomadas fotográficas e acessar informações de voo. A captura fotográfica pode ser autônoma ou manual através de aplicativos para smartphone.

Nas capturas fotográficas do Edifício $E 1$, o drone foi controlado via aplicativo do mesmo fabricante, no qual é possível controlar e verificar visualmente a captura, ajustar o foco ao objeto de interesse, ajustar a inclinação da câmera, além de acessar demais dados de voo como altura em relação ao solo, velocidade, níveis de bateria, posição em mapa integrado.

O fluxo de trabalho utilizado para restituição fotogramétrica do E1 consistiu nas seguintes etapas: (1) Planejamento de tomadas fotográficas visando otimizar o tempo de trabalho de campo (adequando à autonomia de voo) e cobrir a máxima área possível, superando árvores e obstáculos; (2) Captura de fotografias aéreas; (3) 
Processamento dados e nuvem de pontos por dense stereo matching; (4) Extração de ortomosaicos e incorporação no modelo BIM.Estas etapas serão descritas nos tópicos seguintesPlanejamento da captura

O edifício $\mathrm{E} 1$ se situa na região central do campus 1 da USP e é implantado com distâncias laterais significativas de outras edificações. Embora a implantação possibilite o levantamento aéreo, há densa vegetação com árvores em praticamente todo o entorno, o que compromete as tomadas fotográficas limitando as visadas possíveis. Ao norte e oeste encontram-se as maiores obstruções, a leste há um distanciamento em função da rua interna do campus e, ao sul, a vegetação é mais espaçada e menos encopada, permitindo área livre próxima ao Monumento Décadas. Assim, as tomadas fotográficas tiveram três objetos principais em função dos obstáculos encontrados: (i) fachada sul, (ii) fachada leste e (iii) cobertura do edifício.

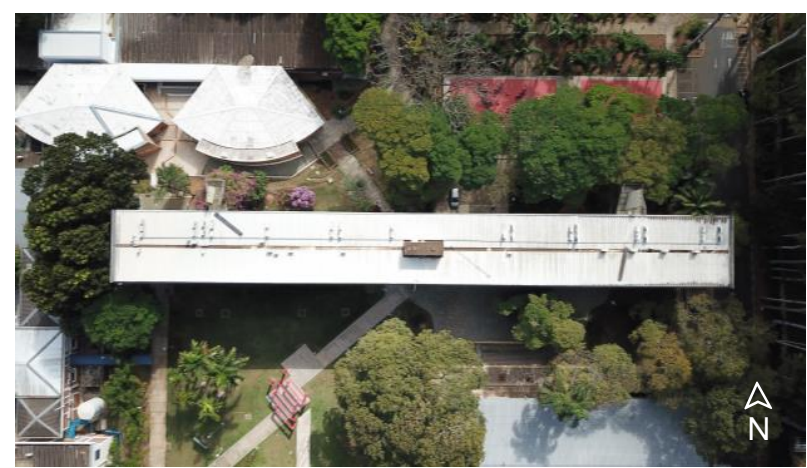

Figura 3: Implantação do edifício a partir de levantamento aéreo realizado. Fonte: Autores.

\section{CAPTURA}

O levantamento cobriu aproximadamente $70 \%$ da fachada sul, $100 \%$ da cobertura e $100 \%$ da fachada leste e foram necessárias seis sessões de voos, totalizando aproximadamente duas horas de voo em 4 horas de Levantamento. Foram tiradas aproximadamente 550 fotos, com sobreposição mínima de $50 \%$ nas manhãs dos dias 23 e 24 de junho de 2018. Em cada tomada, teve-se a preocupação de ajustar o foco da câmera aos objetos de interesse e procurou-se evitar sombreamentos intensos e excessiva incidência de luz. As imagens com problemas de foco e iluminação foram eliminadas manualmente em laboratório. Nas Figuras 4, 5 e 6 é apresentada - com pontos pretos - a localização do drone em cada fotografia.

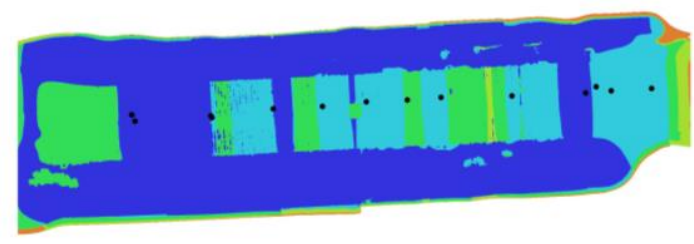

$20 \mathrm{~m}$

Figura 4: Localização de tomadas fotográficas da Cobertura. Fonte: autores

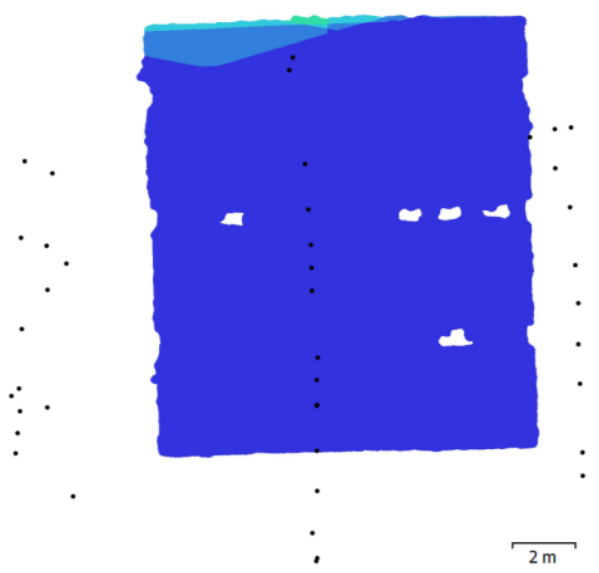

Figura 5: Localização de tomadas fotográficas da Fachada Leste. Fonte: autores

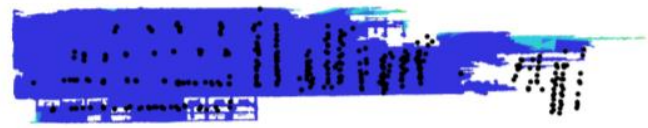

$20 \mathrm{~m}$

Figura 6: Localização de tomadas fotográficas da Fachada Sul. Fonte: autores

\section{PROCESSAMENTO DE DADOS}

A restituição fotogramétrica foi realizada com software Agisoft Photoscan, empregando a técnica Dense Stereo Matching (DSM), processo semiautomático para correlacionar imagens e gerar nuvens de pontos tridimensionais. O processamento foi realizado de forma separada para cada face da edificação, de modo que os resultados foram individualmente obtidos para as faces Sul, Leste e Cobertura.

A nuvem de pontos gerada no processo de fotogrametria foi desenvolvida em três etapas no Agisoft Photoscan. Primeiramente, as imagens foram alinhadas as partir das coordenadas geográficas de cada foto e foi gerada uma nuvem densa de pontos. Na segunda etapa a nuvem foi segmentada para a criação da malha texturizada. Por fim, foram gerados e exportados os ortomosaicos de fotos de cada face levantada.

\section{MODELAGEM BIM}

A modelagem BIM foi desenvolvida no software Autodesk Revit 2019. A modelagem as-designed foi realizada previamente ao levantamento aéreo, baseando-se na documentação levantada junto à administração da USP, de modo que os ortomosaicos resultantes foram incorporados ao modelo como entrada de dados para correções, incorporação de informações inexistentes e/ou inconsistentes e elaboração de modelo as-is.

\section{RESULTADOS}

Os principais resultados desse trabalho são: (i) os ortomosaicos gerados das faces estudadas do edifício 
que possibilitam a documentação as-is da edificação; e (ii) a incorporação do ortomosaicos em vistas bidimensionais do modelo BIM em desenvolvimento.

\section{ORTOMOSAICOS}

$\mathrm{Na}$ Cobertura, documentam-se as modificações realizadas posteriormente à construção do edifício como telhas de aço de perfil trapezoidal, instalações de arcondicionado ao longo de todo comprimento. Nota-se também o acúmulo excessivo de sujeira em calhas e rufos, destacado na Figura 7, o qual pode comprometer o bom funcionamento dos sistemas de água pluvial.
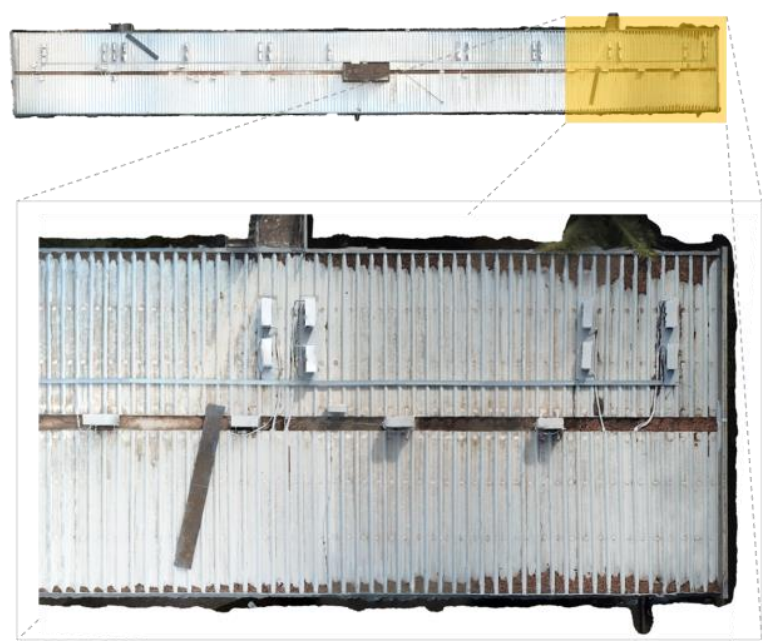

Figura 7: Ortomosaico da Cobertura do Edifício E1. Fonte: autores.

$\mathrm{Na}$ Fachada Leste - Figura 8 - documentam-se manifestações patológicas como rachaduras, manchas e pequenos danos aos acabamentos externos.

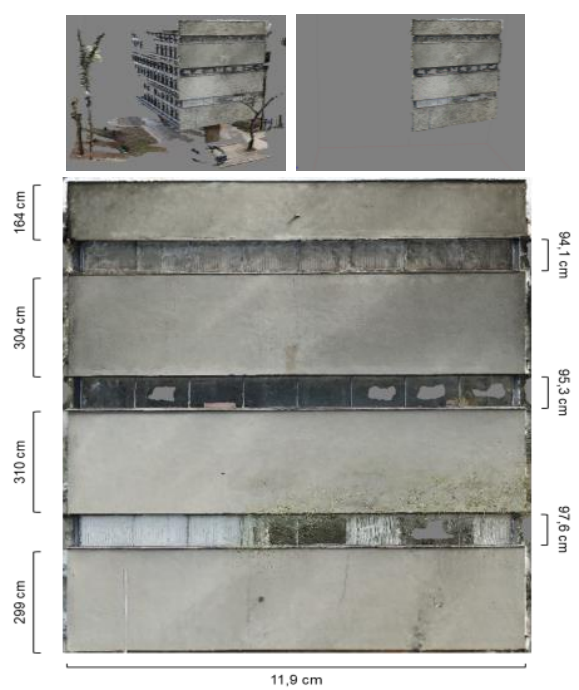

Figura 8: Processo de segmentação e geração de ortomosaico da Fachada Leste. Fonte: autores.

Na Fachada Sul - Figura 9 - os resultados são parciais em função da obstrução causada por árvores na região à direita e no canto esquerdo.

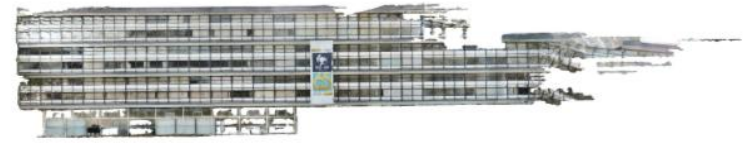

Figura 9: Ortomosaico da Fachada Sul. Fonte: autores.

\section{INTEGRAÇÃO COM BIM}

$\mathrm{Na}$ Figura 10 apresenta-se a incorporação do ortomosaico à vista de implantação no modelo BIM.

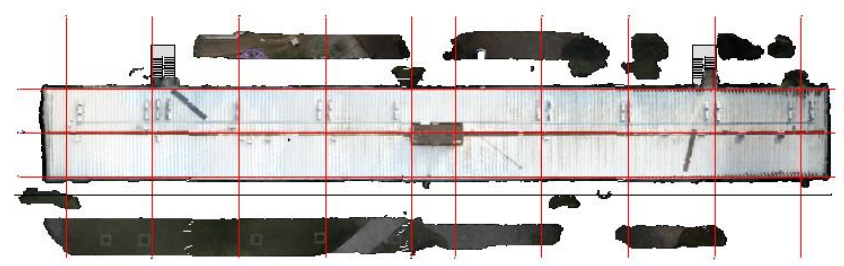

Figura 10: Ortomosaico do Telhado incorporado ao modelo BIM. Fonte: autores.

A Figura 11 apresenta a incorporação do ortomosaico da Fachada Leste

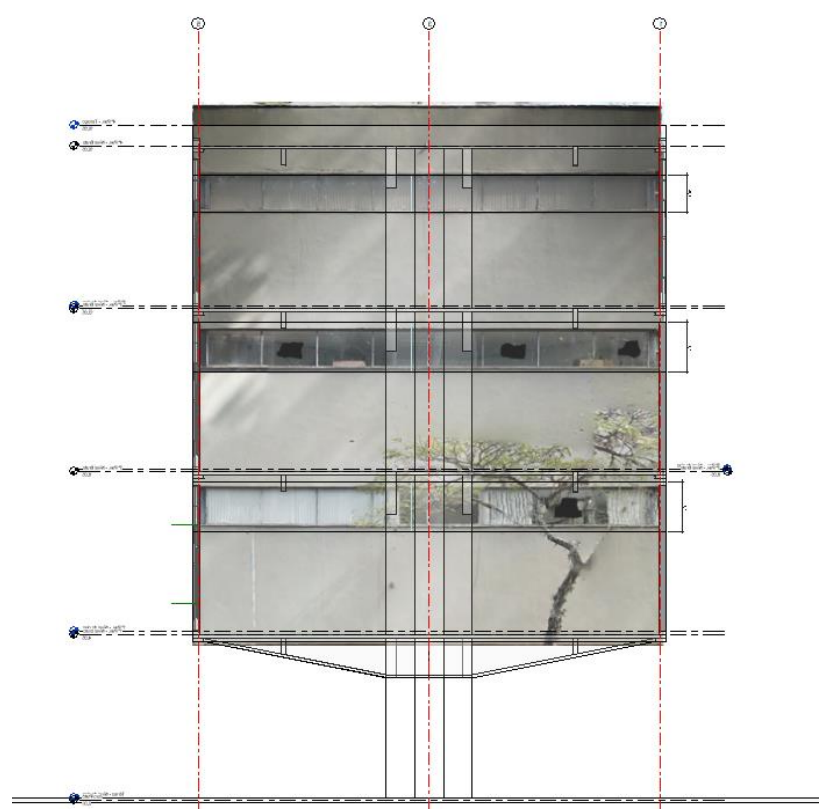

5

Figura 11: Ortomosaico da Fachada Leste incorporado ao modelo BIM. Fonte: autores.

E, por fim, apresenta-se na Figura 12[a] uma justaposição lado-a-lado do ortomosaico (à esquerda), do modelo BIM (à direita) e da sobreposição de ambos (no centro). Na Figura 12[b] observa-se a vista da Fachada Sul com o mosaico sobreposto, no Autodesk Revit. 


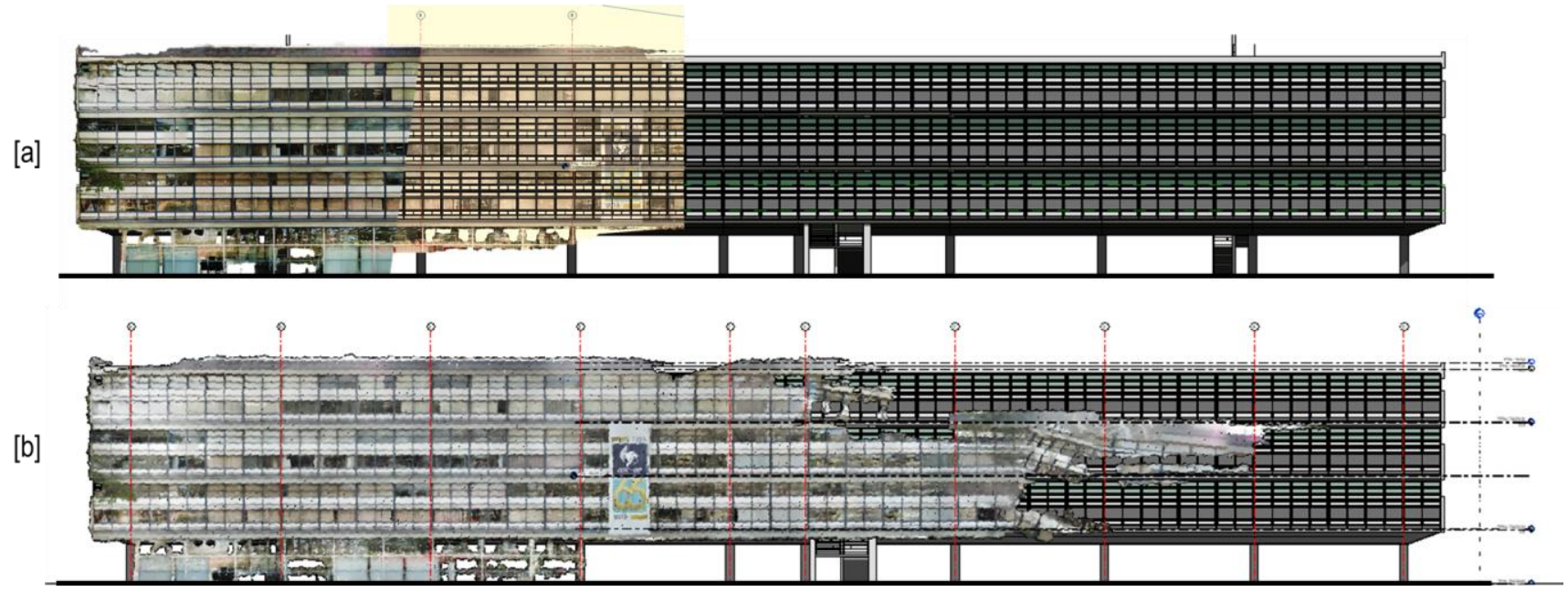

Figura 12: [a] Da esquerda para direita, composição: (i) Ortomosaico; (ii) Ortomosaico + BIM; e (iii) BIM. [b] Ortomosaico da Fachada sul incorporado ao modelo BIM. Fonte: autores.

Este artigo demostrou os resultados do uso de tecnologias de digitalização tridimensionais com intuito de preencher lacunas de informações projetuais para fins de documentação técnica de edificações. Os resultados colaboram para o modelo BIM as-is em desenvolvimento documentando informações outrora desconhecidas em razão do difícil acesso físico. Além disso, os materiais elaborados permitem avanços no desenvolvimento de uma referência documental de características espaciais da edificação em questão.

O trabalho em questão tem caráter inicial e exploratório de emprego de tecnologias de digitalização por fotogrametria aérea, no entanto, consideram-se positivos os resultados encontrados como análises preliminares da documentação espacial e de levantamento de patologias.

Na Fachada Sul Figura 12, notam-se falhas significativas na geração da nuvem de pontos e, consequentemente na malha, textura e ortomosaico. No entanto, há na região central condições melhores de visada e, consequentemente, resultados mais consistentes para análises dos seus elementos, como a disposição de caixilhos e a tomada de medidas para auxílio à modelagem BIM.

Há falhas no georreferenciamento das nuvens geradas, sendo necessários novos levantamentos, desta vez, amparados com pontos de controle de GPS de alta precisão. Analisa-se, também, a possibilidade de incorporação de marcos geodésicos registrados nos campi como forma de georreferenciamento.

Pretende-se incorporar as nuvens de pontos geradas diretamente ao modelo BIM para que a reconstituição geométrica do edifício tenha bases dimensionais consistentes. Considera-se a realização de novos levantamentos com o emprego de otimizações do controle da câmera aprendidas no processo de desenvolvimento deste trabalho.
Por fim, o método estabelecido para o levantamento se mostrou adequado e com qualidade dimensional satisfatória dos resultados encontrados. Os objetivos de gerar ortomosaicos fotográficos e inseri-los na modelagem BIM foram atendidos no sentido de registro documental do patrimônio. Contudo, há necessidade da incorporação, mesmo que emulada, da nuvem de pontos diretamente no modelo BIM para que o produto as-is final seja mais consistente e permita melhor apoio à modelagem.

\section{AGRADECIMENTOS}

À FAPESP pelo apoio e subsídio ao desenvolvimento da pesquisa, processo ํㅡ 2017/24896-4.

Ao Conselho Nacional de Desenvolvimento Científico e Tecnológico (CNPq) pelo auxílio a pesquisa.

\section{REFERÊNCIAS}

ANDRADE, M.L.V.X. de; RUSCHEL, R. C. Building Information Modelling. In: KOWALTOWSKI, D.C.C.K.; MOREIRA, D.de C.; PETRECHE, J.R.D.; FABRÍCIO, M.M.. (Org.). O processo de projeto em Arquitetura: da teoria à tecnologia.. 1ed.São Paulo: Oficina de Textos, 2011, v., p. 421-442.

CANUTO, C.L.; MOURA, L.R.; SALGADO, M. S. Tecnologias digitais e preservação do patrimônio arquitetônico: explorando alternativas. PARC Pesquisa em Arquitetura e Construção, Campinas, SP, v. 7, n. 4, p. 252-264, dez. 2016. ISSN 1980-6809.

Doi:https://doi.org/10.20396/parc.v7i4.8647456.

DEZEN-KEMPTER, E.; SOIBELMAN, L.; CHEN, M.; MÜLLER, A.V. Escaneamento 3D a laser, fotogrametria e modelagem da informação da construção para gestão e operação de edificações históricas. Gestão e Tecnologia de Projetos, São Paulo, v. 10, n. 2, p. 113-124, jul./dez. 2015. Doi: http://dx.doi.org/10.11606/gtp.v10i2.102710

EASTMAN, Chuck et al. Manual de BIM: um guia de modelagem da informação da construção para arquitetos, engenheiros, gerentes, construtores e incorporadores. Porto Alegre: Bookman, 2014.

FOSTER, S.; HALBSTEIN, D. Integrating 3D Modeling, Photogrammetry and Design. London: Springer, 2014

FRITSCH, D. Virtual cities and landscape models - what has photogrammetry to offer? Virtual Reality, p. 3-14, 1999. 
GUIMARÃES, A. L.; GROETELAARS, N. J.; AMORIM, A.

L. Modelagem BIM a partir de nuvem de pontos e restituição fotograqmétrica: estudo de caso para documentação arquitetônica. In: II Seminário Nacional de Documentação do Patrimônio Arquitetônico com Uso de Tecnologias Digitais, 1, 2012, Belém, PA. Anais (online).

GROETELAARS, N. J.; AMORIM, A. L. Dense Stereo Matching (DSM): conceitos, processos e ferramentas para criação de nuvens de pontos por fotografias. In: SIGraDi 2012. 16., nov. 2012, Fortaleza.

LINDER, W. Digital photogrammetry a practical course. Springer Berlin Heidelberg New York, 2009.

NOSELLA, P.; BUFFA, E. Escola de Engenharia de São Carlos. Os primeiros tempos: 1948-1971. São Carlos: EDUFSCAR, 2000.

NOBRE, Ana Luiza. Módulo Só. O edifício E1, em São Carlos, de Ernest Mange e Hélio Duarte. Risco: Revista de Pesquisa em Arquitetura e Urbanismo (on line), v. 5, p. 22-32, 2007. Disponível em:

<https://www.revistas.usp.br/risco/article/download/44687/ 48310>. Acesso em: 23 jun. 2018.

PENTTILÄ, H.; RAJALA, M.; FREESE, S. Building Information Modelling of Modern Historic Buildings - Case study of HUT/Architectural Department by Alvar Aalto. In: Proceedings of the 25th eCAADe Conference, Frankfurt/Wiesbaden, Germany, pp. 607-613. 